\title{
Hemoglobin determination with paired emitter detector diode
}

\author{
Elżbieta Mieczkowska • Robert Koncki • \\ Lukasz Tymecki
}

Received: 1 September 2010 /Revised: 12 October 2010 /Accepted: 18 October 2010/Published online: 3 November 2010

(C) The Author(s) 2010. This article is published with open access at Springerlink.com

\begin{abstract}
Two ordinary green light-emitting diodes used as light emitter and detector coupled with simple voltmeter form a complete, cost-effective prototype of a photometric hemoglobinometer. The device has been optimized for cuvette assays of total hemoglobin ( $\mathrm{Hb}$ ) in diluted blood using three different chemical methods recommended for the needs of clinical analysis (namely Drabkin, lauryl sulfate, and dithionite methods). The utility of developed device for real analytics has been validated by the assays of total $\mathrm{Hb}$ content in human blood. The results of analysis are fully compatible with those obtained using clinically recommended method and clinical analyzer.
\end{abstract}

Keywords Hemoglobin · Blood · Photometry · Paired emitter detector diode

\section{Introduction}

Economic, miniature, low-power, and field-deployable analytical tools are required for many kinds of analyses performed outside specialized laboratories like biomedical tests at home or surgery, food quality control, environmental screening and monitoring, etc. [1-5]. As a large number of analytes are colored or could be easily and selectively converted into colored species, the predominant position

Published in the special issue Focus on Analytical Science in Poland (VIIIth Polish Conference on Analytical Chemistry) with Guest Editor Pawel Koscielniak.

E. Mieczkowska $\cdot$ R. Koncki $\cdot$ Ł. Tymecki $(\triangle)$

University of Warsaw, Department of Chemistry,

Pasteura 1,

02-093 Warsaw, Poland

e-mail: luktym@chem.uw.edu.pl of photometric methods in this field of modern analytics as well as the reasons for investigations and development of novel systems for optical measurements are obvious. For many analytical uses, simple dedicated photometric devices based on economic optoelectronic components are sufficient.

Light-emitting diodes (LEDs) are the simplest and cheapest optoelectronic components, mass-produced in semiconductor technology. These extremely robust, lowpower, and intensive light emitters, offering narrow emission spectra covering broad spectral range from UV to NIR, are widely applied in photometric systems as effective light sources [6,7]. On the other hand, it is known that the internal photoelectric effect (opposite to electroluminescence phenomenon) allows the use of LEDs as light detectors [8-11]. Thus, the pairing of two LEDs, playing the roles of light emitter and detector, leads to construction of a complete photometric device useful in analytical chemistry. Such paired emitter detector diode (PEDD) photometers generate reproducible, hundredmillivolts-large analytical signals [9-11]. As an example, a complete PEDD-based photometer made of two red LEDs coupled with an ordinary voltmeter, developed for education needs and useful as an efficient analytical tool for determination of blue dyes, $\mathrm{pH}$, and $\mathrm{pH}$-indicators as well as for kinetic assays of enzymes activity, has been demonstrated only recently [11].

In this note, a very simple PEDD-based device dedicated for photometric determination of hemoglobin $(\mathrm{Hb})$ is presented. Contrary to other prototypes of $\mathrm{Hb}$ meters recently reported in the literature [12, 13], this fibreless device is fabricated without the use of any advanced technologies, electronics nor optoelectronics. The utility of the developed device for real analytics will be validated by the assays of total $\mathrm{Hb}$ content in human blood. 


\section{Experimental}

Lyophilized hemoglobin, sodium lauryl sulfate (SLS) and sodium dithionite $\left(\mathrm{Na}_{2} \mathrm{~S}_{2} \mathrm{O}_{4}\right)$, were obtained from SigmaAldrich (USA). Other reagents of analytical grade were obtained from POCh (Poland). Doubly distilled water was used throughout.

Six kinds of $5-\mathrm{mm}$ diameter LEDs $(525 \mathrm{~nm} / 10 \mathrm{Cd}$, $565 \mathrm{~nm} / 0.8 \mathrm{Cd}, 570 \mathrm{~nm} / 1.5 \mathrm{Cd}, 600 \mathrm{~nm} / 1.5 \mathrm{Cd} ; 630 \mathrm{~nm} /$ $1.5 \mathrm{Cd}$ and $650 \mathrm{~nm} / 4 \mathrm{Cd}$ ) used in these investigations were obtained from Optosupply (Hong Kong). Paired LEDs were mounted into cuvette holder made of Lego bricks, shown elsewhere $[9,11]$. Electromotive force generated by tested PEDDs, treated as an analytical signal, was measured and recorded with Axiomet multimeter (model AX-18B, China).

Reference spectrophotometric measurements were performed using Shimadzu spectrophometer (model 2401/ PC, Japan). For all experiments, disposable $1 \times 1 \times 4 \mathrm{~cm}^{3}$ polystyrene cuvettes (Sarstedt, Germany) were used.

\section{Results and discussion}

\section{Spectrochemistry of $\mathrm{Hb}$}

Figure 1 presents color and corresponding spectra for 100 to 500 fold diluted blood and different forms of $\mathrm{Hb}$ at comparable concentrations. Hemoglobin forms an unstable, reversible bond with oxygen. This oxygen-loaded form named oxyhemoglobin $\left(\mathrm{HbO}_{2}\right)$ is bright red. In the oxygenunloaded form, it is called deoxyhemoglobin $(\mathrm{Hb})$ and is purple-blue. Additionally, blood samples may contain carbaminohemoglobin (unstable compound of $\mathrm{Hb}$ and carbon dioxide) which is bluish in color and carboxyhemoglobin (a stable complex of $\mathrm{Hb}$ and carbon monoxide) which is bright, cherry red. Lyophilized $\mathrm{Hb}$ available as reagent, similarly as the native forms of $\mathrm{Hb}$, is readily oxidized in air so its preparations predominantly contain methemoglobin (MetHb) forming brownish solutions having four absorbance peaks in visible range of spectrum. Simultaneous multiwavelength absorbance measurements permitted the composition of $\mathrm{Hb}$ pigment mixtures to be determined. However, such approach is easily implemented only with a precise microprocessorcontrolled spectrophotometer [14-16].

An alternative approach useful for determination of total $\mathrm{Hb}$ is based on chemical conversion of all $\mathrm{Hb}$ fractions into one stable form [16]. The most popular and widely accepted in clinical settings is the cyanmethemoglobin (hemiglobincyanide, $\mathrm{HiCN}$ ) method used as the international standard procedure for hemoglobin $(\mathrm{Hb})$ determinations due to the accuracy, stability and availabil-

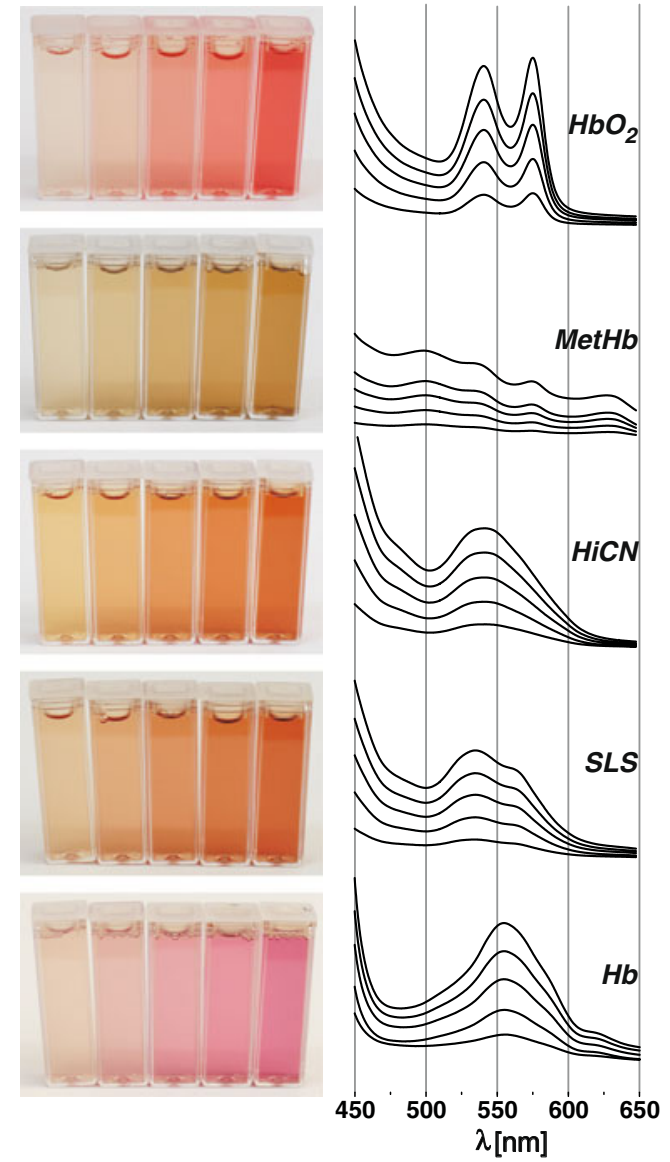

Fig. 1 Color and spectra of selected Hb forms. Description in the text

ity of a stable reference standard/calibrator [16, 17]. HiCN has one absorbance peak at $542 \mathrm{~nm}$ (Fig. 1). Unfortunately, the presence of potassium cyanide and potassium ferricyanide in the reagents constitutes a potential toxic hazard and problems of laboratory and environmental pollution. As an alternative, conversion of hemoglobin to a sulfate derivative by non-toxic SLS has been proposed $[18,19]$. This reagent converts all fractions of $\mathrm{Hb}$ into stable SLS-MetHb form exhibiting maximal absorbance at $536 \mathrm{~nm}$ (Fig. 1). Another methodology is based on deoxygenation/reduction of all $\mathrm{Hb}$ fractions (including MethHb) with sodium dithionite [20,21] to $\mathrm{Hb}$ form exhibiting one absorbance peak at $555 \mathrm{~nm}$ (Fig. 1).

In the course of primary measurements performed with spectrophotometer (Fig. 1), it has been found that $\mathrm{Hb}$ standards prepared using lyophilized powder are stable over time, whereas the spectra of blood standards slightly change in a random way. The predominant forms in reagent and blood solutions are MetHb and $\mathrm{HbO}_{2}$, respectively. In both cases, absorbances of diluted solutions stay in agreement with Lambert-Beer's law (Fig. 1). 
Fig. 2 The effect of PEDD driving current on sensitivity of $\mathrm{Hb}$ determination. Results for four possible PEDD combinations constructed of 565 and $570 \mathrm{~nm}$ LEDs

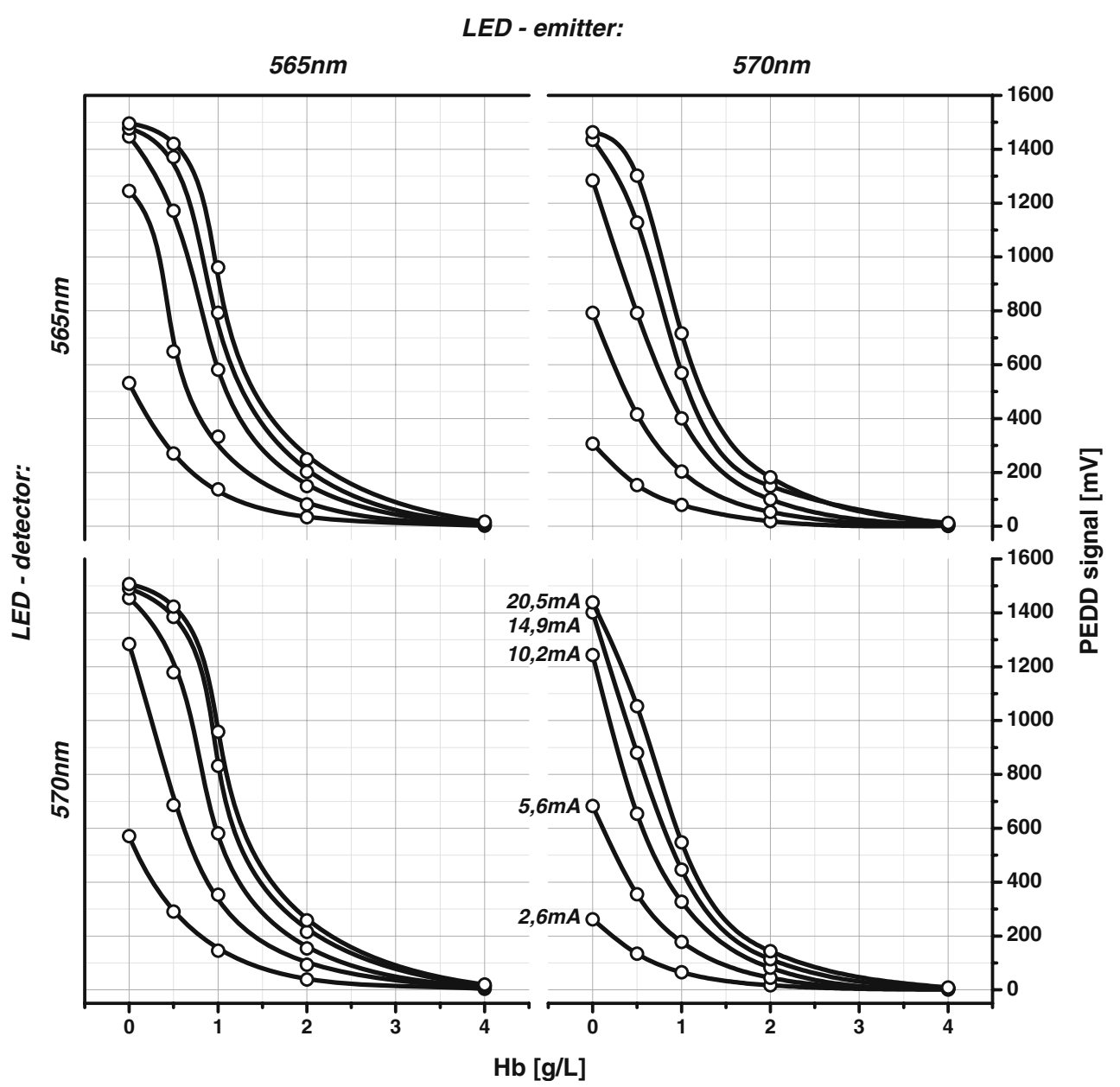

Both kinds of original standards were modified with Drabkin reagent $\left(1.5 \mathrm{mM} \mathrm{KCN}+1.0 \mathrm{mM} \mathrm{K}_{3} \mathrm{Fe}(\mathrm{CN})_{6}\right)$, SLS $(0.35 \%)$, and dithionite $(0.1 \mathrm{M})$ leading to HiCN, SLS$\mathrm{MetHb}$, and $\mathrm{Hb}$ forms, respectively. The stable standards prepared by HiCN, SLS, and dithionite methods were obtained within 20,5 , and $2 \mathrm{~min}$, respectively. The color and corresponding spectra of modified standards are shown in Fig. 1. The spectra of modified standards are identical, stable over many hours and consistent with Lambert-Beer's law, independently of kind of used original standard (lyophilized reagent or blood). It means that in case of the mentioned methods, the standards prepared of lyophilized $\mathrm{Hb}$ are useful for real blood analysis.

\section{Hb-PEDD characteristics}

All 36 PEDD combinations possible to construct using LEDs itemized in the "Experimental" section were tested as potential photometric $\mathrm{Hb}$ detectors. For PEDDs where the wavelength of LED emitter was significantly shorter than for the LED used as light detector, the lack of sensitivity was observed, which is in agreement with earlier findings $[9,10]$. Taking into account the sensitivity criterion, the best results are offered by PEDDs constructed using 565and 570-nm LEDs as their emission spectra are the most compatible with absorption spectra of various $\mathrm{Hb}$ forms. The calibrations graphs for such four PEDD combinations (Fig. 2) have been obtained using $\mathrm{Hb}$ standards modified with dithionite. In the course of analogous experiments with standards prepared using SLS and HiCN method the same PEDDs were found to be the most promising. The sensitivities for the linear range of detection $(0-1,000$ $\mathrm{mg} / \mathrm{L}$ ), obtained at $15 \mathrm{~mA}$ PEDD driving current for SLS, HiCN, and dithionite methods were $1.03 \pm 0.04$, $1.11 \pm 0.07$, and $1.25 \pm 0.08 \mathrm{mV} / \mathrm{mg} / \mathrm{L}$, respectively. As expected, the highest sensitivity was observed for dithionite method, because in this case the absorption spectrum of analyte (Fig. 1) is the most compatible with the emission spectrum of used LED.

The calibration graphs shown in Fig. 2 were obtained at various currents driving tested PEDDs. As it was reported earlier [10], it is possible to adjust the range of maximal sensitivity to the required range of detection by the appropriate choice of power supplying this device. The optimal PEDD driving currents for investigated range of $\mathrm{Hb}$ concentration (consistent with $\mathrm{Hb}$ levels in 


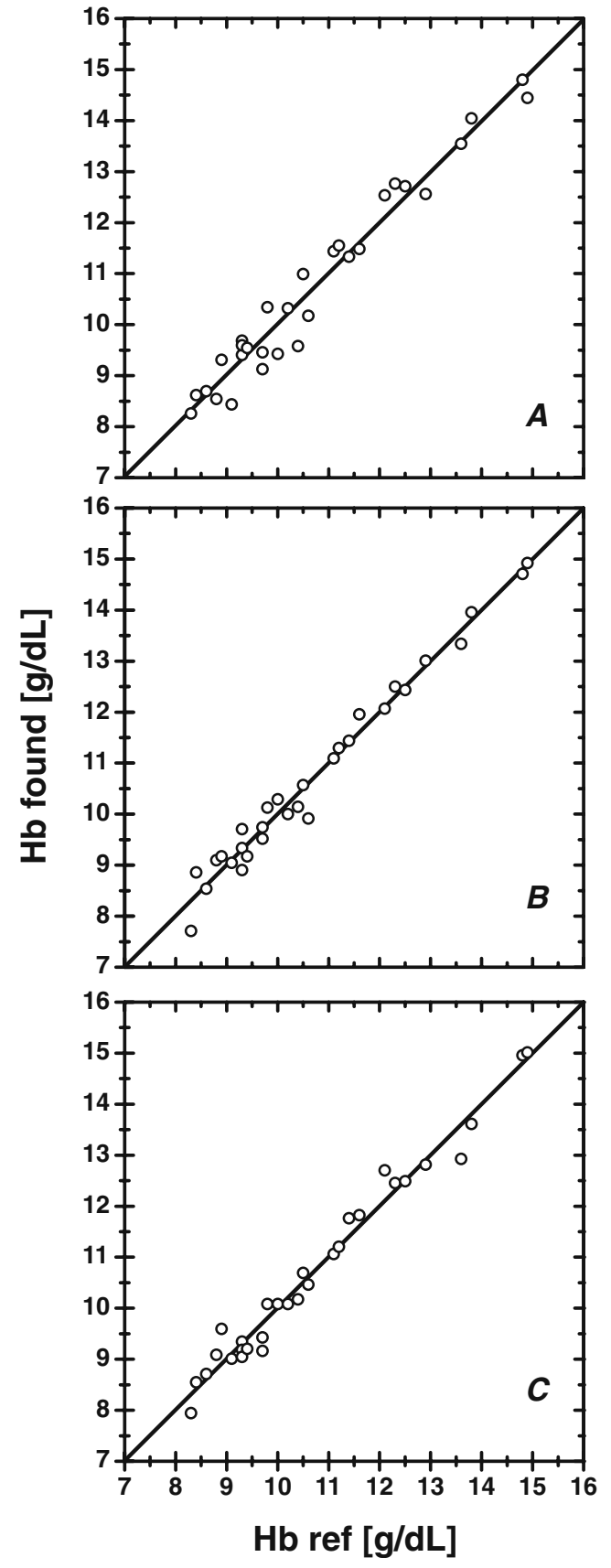

Fig. 3 Correlation between results of blood analysis obtained using developed 570/570 nm PEDD detector and reference method recommended for clinical uses. Results for 30 human blood samples 200-folddiluted with Drabkin reagent (a), SDS (b), and dithionite (c)

100-500-fold-diluted blood samples) are lower than maximal currents $(30 \mathrm{~mA})$ recommended for LED supplying. It is worth noticing that at currents lower than $20 \mathrm{~mA}$ where no saturation of analytical signal for diluted samples is observed, it is possible to detect $\mathrm{Hb}$ concentrations lower than $0.01 \mathrm{~g} / \mathrm{dl}$. Normal $\mathrm{Hb}$ content in human blood varies from 11 to $16 \mathrm{~g} / \mathrm{dl}$ and decreases in case of anemia diseases.
Blood analysis

The developed prototype of hemoglobinometer based on $570 / 570 \mathrm{~nm}$ PEDD operating at $15-\mathrm{mA}$ driving current was validated with 30 real samples of human blood containing $\mathrm{Hb}$ at physiological as well as pathological levels. Before measurements, blood samples were 200 -fold-diluted with reagent solutions for $\mathrm{HiCN}$, SLS, or dithionite methods. Thus, for single determination, less than $0.02 \mathrm{~mL}$ of blood was required. Reference determinations of total $\mathrm{Hb}$ were performed by hospital laboratory using clinical photometric HiCN analyzer XT-2000i/XT (SYSMEX, Japan). As can be seen from Fig. 3, the results of analysis with the developed detector are fully compatible with those obtained using the reference method. The regression coefficient for $\mathrm{HiCN}$, SLS, and dithionite methods are 0.9580, 0.9782, and 0.9752 , respectively. Such results are acceptable in case of manual analysis.

\section{Conclusions}

In this communication, a complete, cost-effective prototype of hemoglobinometer constructed of only two ordinary green LEDs coupled with simple voltmeter is presented. The price of two LEDs is lower than a half euro whereas the total cost of electronics for PEDD supplying and signal recording is only a few euros. Its practical utility for real analytics has been confirmed by the results of human blood analysis fully compatible with those obtained using clinically recommended method and analyzer.

Although the presented PEDD detector is extremely simple, its potential applications for development of advanced bioanalytical systems dedicated for more specific clinical applications are attractive. As shown elsewhere [22, 23], PEDDs are easily applicable as flow-through detectors in various flow analysis systems. Thus, PEDD-based detectors could be easily miniaturized and integrated with separation chromatographic or electrophoretic devices potentially leading to dedicated analytical tools useful for determination of selected $\mathrm{Hb}$ fractions recognized as specific markers for diabetes $[24,25]$, thalassemia $[26,27]$, etc.

Acknowledgments The investigations were performed in the frame of undergraduate student project (EM licentiate) supported by the Ministry of Science and Higher Education (Project no. NN204 029636). Analyzed samples of human blood were obtained from Medical University of Warsaw (MUW). Helpful assistance and comments from Dr. Agnieszka Wiśniewska (Department of Laboratory Diagnostics, MUW) are kindly acknowledged.

Open Access This article is distributed under the terms of the Creative Commons Attribution Noncommercial License which permits any noncommercial use, distribution, and reproduction in any medium, provided the original author(s) and source are credited. 


\section{References}

1. Kostov Y, Rao G (2000) Rev Sci Instum 71:4361-4374

2. Wang J (2002) Trend Anal Chem 21:226-232

3. Wang J (2004) Anal Chim Acta 507:3-10

4. Weigl B, Domingo G, La Barre P, Gerlach J (2008) Lab Chip 8:1999-2014

5. Kieckle FL, Holland CA (2009) Clin Lab Med 29:555-560

6. Dasgupta PK, Eom IY, Morris KJ, Li J (2003) Anal Chim Acta 500:337-364

7. O'Toole M, Diamond D (2008) Sensors 8:2453-2479

8. Lau KT, Baldwin S, O’Toole M, Shepherd R, Yerazunis WJ, Izuo S, Ueyama S, Diamond D (2006) Anal Chim Acta 557:111-116

9. Tymecki Ł, Pokrzywnicka M, Koncki R (2008) Analyst 133:1501-1504

10. Tymecki Ł, Koncki R (2009) Anal Chim Acta 639:73-77

11. Pokrzywnicka M, Koncki R, Tymecki Ł (2009) Chem Anal 54:427-435

12. Noda T, Takao H, Yoshioka K, Oku N, Ashiki M, Sawada K, Matsumoto K, Ishida M (2005) Sens Act B 119:245-250

13. Weiwei Y, Aiyu Z, Baoshan H, Xinxia C (2008) Sens Act B 130:21-24

14. Zwart A, Buursma A, van Kampen EJ, Zijlstra WG (1984) Clin Chem 30:373-379
15. Zijlstra WG, Buursma A, Zwart A (1988) Clin Chem 34:149152

16. Zijlstra WG, Buursma A, van Assendelft OW (2000) Visible and near infrared absorption spectra of human and animal haemoglobin: determination and application. VSP, Boston

17. van Kampen EJ, Zijlstra WG (1961) Clin Chim Acta 6:538544

18. Oshiro I, Takenaka T, Maeda J (1982) Clin Biochem 15:8388

19. Lewis SM, Garvey B, Manning R, Sharp SA, Wardle J (1991) Clin Lab Haematol 13:279-290

20. Dalziel K, O'Brien JRP (1957) Biochem J 67:119-124

21. Hamada K, Okazaki T, Shukuya R, Kaziro K (1962) J Biochem 52:374-376

22. Tymecki Ł, Brodacka L, Rozum B, Koncki R (2009) Analyst 134:1333-1337

23. Tymecki Ł, Strzelak K, Koncki R (2009) Talanta 79:205-210

24. Halwachs-Baumann G, Katzensteiner S, Schnedl W, Purstner P, Pieber T, Wilders-Truschnig M (1997) Clin Chem 43:511517

25. Bay L, Chen PC, Sacks DB (2001) Clin Chem 47:153-163

26. Srisawang B, Kongtawelert P, Hartwell SK, Jakmunee J, Grudpan K (2003) Talanta 60:1163-1170

27. Hartwell SK, Srisawang B, Kongtawelert P, Christian GD, Grudpan K (2005) Talanta 65:1149-1161 